\title{
Erratum zu: Pankreas
}

Tobias Keck, Dietlind Tittelbach-Helmrich, Ulrich T. Hopt

\section{Erratum zu: Kapitel 37 in:}

H. Hauser et al. (Hrsg.), Akutes Abdomen, DOI 10.1007/978-3-7091-1473-5_37

Folgende Abbildungen mussten aufgrund eines drucktechnischen Qualitätsmangels ausgetauscht werden: • Abb. 37.3, • Abb. 37.5 und $\bullet$ Abb. 37.7

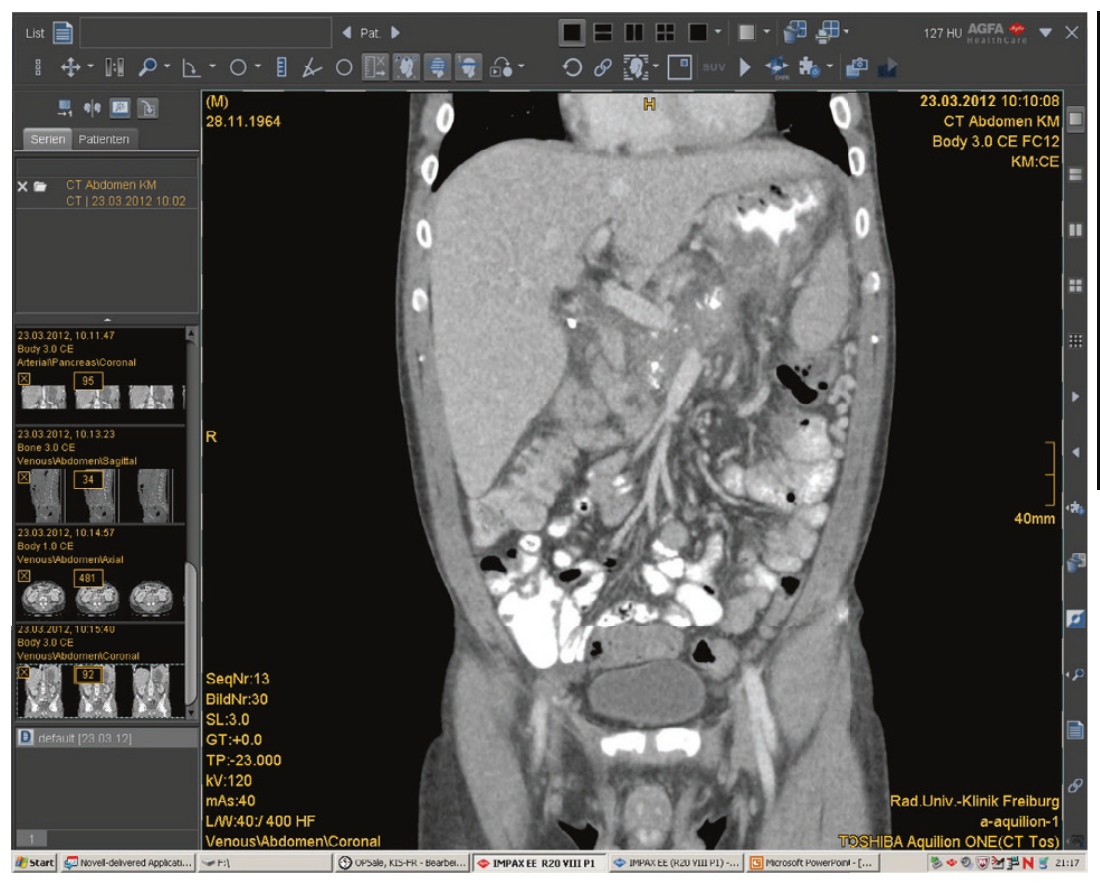

a

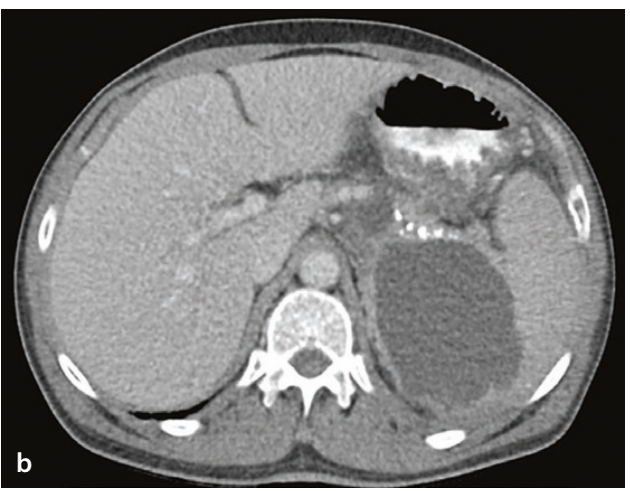

- Abb. 37.3 CT mit Verkalkungen des Pankreas sowie Ausbildung einer Pseudozyste im Bereich der Cauda pancreatis bei chronischer Pankreatitis. a Ausgeprägte Verkalkungen im Pankreaskopf und Pankreasschwanz bei chronischer Pankreatitis, $\mathbf{b}$ ausgeprägte Pseudozyste im Pankreasschwanzbereich mit angrenzenden Kalzifikationen 

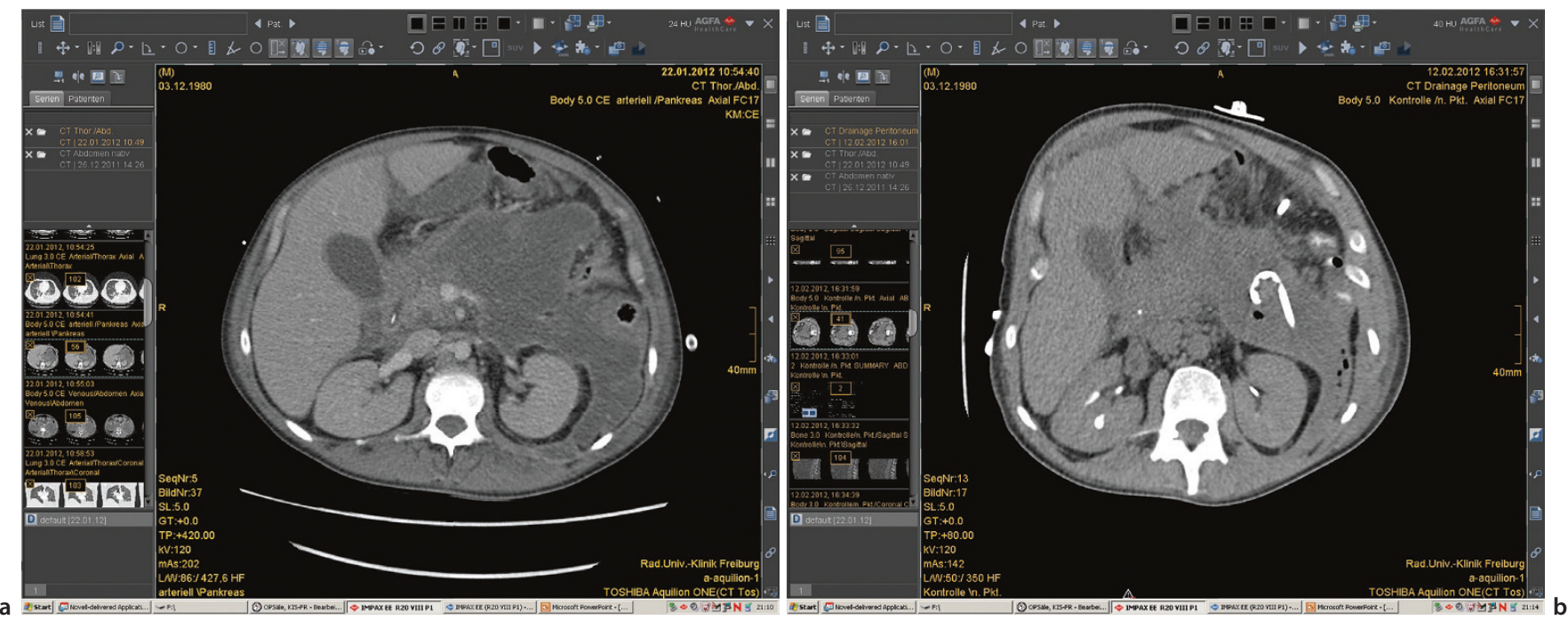

- Abb. 37.5 a Ausgeprägter Abszess in der Bursa omentalis und linkslateral im Retroperitoneum als Folge einer nekrotisierenden Pankreatitis. Der Magen liegt der Flüssigkeitssammlung nicht an. b Linkslaterale CT-gestützte Punktion und Drainage in Sinne eines Step-up-Verfahrens
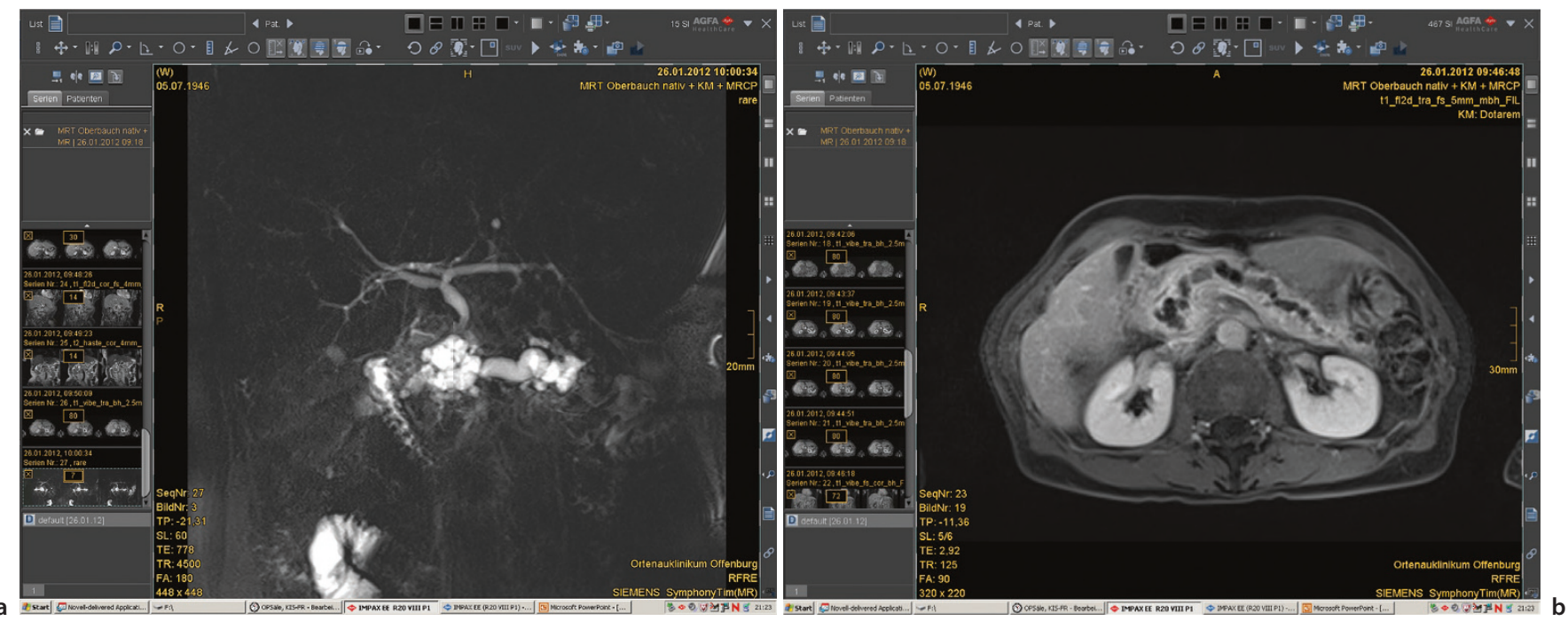

- Abb. 37.7 a MRT und MRCP eines Karzinoms aus einer main duct type IPMN im Pankreaskopf; Histologie: invasiv duktales Pankreaskopfkarzinom pT3 pN1 L1 V0 Pn1, b Abbruch des Pankreasgangs sowie des D. choledochus im Bereich des Pankreaskopfs in der MRCP bei Pankreaskopfkarzinom 